\title{
Interleukin-35 Level in Acne Vulgaris
}

Talal Ahmed Abd El-Raheem ${ }^{1}$, Olfat Gmeel Shaker², Mohamed Hassan Mohamed ${ }^{1}$, Haiba Ali Mohamed*1

${ }^{1}$ Department of Dermatology, STDs and Andrology, Faculty of Medicine, Fayoum University, Egypt

${ }^{2}$ Department of Biochemistry, Faculty of Medicine, Cairo University, Egypt

*Corresponding author: Haiba Ali Mohamed, Mobile: (+20) 01142355587, E-Mail: haibaaly@ gmail.com

\begin{abstract}
Background: Acne vulgaris is a multifactorial disease affects the pilosebaceous follicle and results in inflammatory and non-inflammatory lesions with certain role of cytokines in its pathogenesis. Interleukin-35 (IL35) cytokine has been shown to exhibit immunosuppressive activities, which are distinct from other members of IL-12 family. IL-35 is also unique in that it is expressed primarily by regulatory T- cells (Tregs) rather than by antigen-presenting cells (APCs).

Objective: To investigate the role of IL-35 in the pathogenesis of acne vulgaris by assessing its levels in lesional skin and serum of patients with acne vulgaris compared with normal individuals.

Patients and methods: 44 subjects were divided into 2 groups: Group 1: It included measurement of serum and tissue level of interleukin 35 in 22 acne vulgaris patients with age group (15-30). All of them were subjected to detailed history taking, dermatological and general examination. Group 2: It included 22 healthy, age, and gender matched individuals as a control group.

Result: Our results show a highly statistically significant difference between acne patient and control regarding IL-35 level in serum and tissue.

Conclusion: Our study may provide evidence that serum and tissue IL-35 are important anti-inflammatory cytokines. They are actively expressed by the sebaceous glands. They have significant higher expression in acne patients. They are hypothesized to play a key role in acne cure at multiple points, through their anti-inflammatory action. This effect may be hindered in acne vulgaris by undiscovered obstacles.
\end{abstract}

Keywords: Acne vulgaris and cytokines, IL-35 anti-inflammatory cytokine.

\section{INTRODUCTION}

Acne vulgaris is the most common dermatosis found in the patients aged between 11 and 30. It is believed that acne affects up to $80 \%$ of persons from this group, or even $100 \%$ of young people. The skin changes appearing in the second decade of life become less intensive with time and usually disappear at the end of this decade, or at the beginning of the third decade of life. However, there are cases when the disease is still present until 30 or even 40 years of age ${ }^{(\mathbf{1})}$.

The microcomedone is a primary change which starts the whole inflammatory cascade. Different factors may induce formation of microcomedones, such as linolenic acid deficiency, excessive secretion of androgens or excess of free lipid acids. Intrafollicular keratinisation of a microcomedone leads to its development into a comedone ${ }^{(2)}$.

Accompanied by excessive production of tonofilaments, desmosomes and keratins $\mathrm{K} 6$ and K16, and together with transglutaminase, it results in development of a keratinised "envelope". Altogether, this process leads to closure of a follicle opening and it impedes removal of the sebaceous gland contents onto the skin surface ${ }^{(3)}$.

The role of cytokines in the pathogenesis of acne is not fully known. The TLR2 receptors play a role in the etiology of acne. Stimulation of TLR2 by P. acnes makes the interleukin 8 and 12 (IL- 8 and IL-
12) concentrations increase. Macrophages surrounding the pilosebaceous unit with TLR2 receptors were histologically described in biopsy material of patients with acne ${ }^{(\mathbf{1})}$.

IL-35 is a heterodimeric protein with two subunits, Epstein-Barr virus induced gene 3 (EBI3) and IL-12p35, which shares EBI3 with IL-27. As a result, both IL-35 and IL-27 are immunosuppressive. It is known that EBI3 is the downstream target molecule of Foxp3, the function marker of Treg cells (4).

To date, research on IL-35 has focused mainly on its relationship with auto-immune diseases, inflammation, and infection ${ }^{(5)}$. Furthermore, it is reported that CD4+ T-cells express IL-35 in human peripheral blood mononuclear cells (PBMCs) ${ }^{(6)}$.

The aim of the study was to determine the role of Interleukin 35 (IL-35) in the pathogenesis of acne vulgaris by measuring its level in lesional skin and serum of patients with acne vulgaris compared to controls.

\section{SUBJECTS AND METHODS}

A case control cross sectional analytical study was conducted in Dermatology, STDs and Andrology department of Fayoum University Hospital (Fayoum, Egypt) between March 2018 and August 2018.

Forty-four participants were included in the study. These subjects were allocated into two equal groups: the patient group included 22 patients and 
the control group included 22 healthy individuals. Diagnosis was made on clinical basis. Patients were of both sexes and their age ranged between (18-35) years.

\section{Ethical considerations:}

The study was approved by the Ethics Board of Fayoum UniversityPrior to the initial interview, the researchers introduced themselves to patients who met the inclusion criteria; each potential patient was fully informed with the purpose and nature of the study and then an informed consent was obtained from participants who accepted to participate in the study. The researchers emphasized that participation in the study is entirely voluntary and withdrawal from the study would not affect the care provided, and confidentiality was assured through coding the data.

\section{Inclusion criteria included:}

- Patients with acne vulgaris.

- Age: more than 18 and less than 35 years.

- Sex: both sexes.

Exclusion criteria included:

- Patients who received any systemic and/or topical acne treatment in the last 3 months.

- Pregnant and lactating females.

- Patients with other dermatological diseases.

- Patients with any systemic illness, autoimmune diseases or infections.

\section{All patients were subjected to the following: 1-Detailed history taking which included: Personal history: name, age, sex, occupation and marital state, present history: onset, course, duration of acne vulgaris, any other skin diseases and associated systemic or autoimmune disease, past history: chronic disease and drug history: topical or systemic treatment for this current or previous attack of the disease.}

2-General examination: Careful general examination was done to exclude the presence of any clinical manifestations of autoimmune, systemic disease or infections.

3- Dermatological examination: To detect site, type, grade of acne vulgaris and any associated skin diseases. Acne grade is rated according to the Global Evaluation Acne (GEA) scale developed by Dreno et al. ${ }^{(7)}$.

4-Laboratory assessment: Measurement of the level of interleukine-35 for all participants (patientscontrol) in their sera and biopsies from skin lesions.

\section{Methods:}

\section{Quantitation of Human Interleukin -35 (IL35): 1-Sampling:}

Five milliliters of peripheral venous blood were collected from each patient and control in plain test tube, left to clot then centrifuged at $2500 \mathrm{rpm}$ for ten minute. The separated serum was stored in aliquots at $-20^{\circ} \mathrm{C}$ until the time for measurement of IL-35 using Human Interleukin-35 ELISA kit provided by Shanghai, China. Cat.No: E0042Hu.

\section{2-Skin biopsy:}

Two mm punch skin biopsy was taken from active acne lesion in the face of all acne patients and normal face skin in all controls, after injecting $1 \mathrm{ml}$ of local anesthesia, under complete aseptic conditions. Systemic and topical antibiotics were prescribed after the procedure. The skin biopsy was weighed and homogenized in $400 \mathrm{ul} \mathrm{PBS}$ then the supernatant was separated in an Eppendorf for measurement of IL-35 concentration.

\section{Test principle:}

This kit uses enzyme-linked immune sorbent assay (ELISA) based on the biotin double antibody sandwich technology to assay the human interleukin 35 (IL-35). Add interleukin-35 (IL-35) to the wells, which are pre-coated with interleukin 35 (IL-35), monoclonal antibody and then incubate. After that, add anti IL-35 antibodies labeled with biotin to unite with streptavidin-HRP, which forms immune complex. Remove unbound enzymes after incubation and washing. Add substrate $\mathrm{A}$ and $\mathrm{B}$, then the solution will turn blue and change into yellow with the effect of acid. The shades of solution and the concentration of human interleukin 35 (IL-35) are positively correlated.

\section{Statistical Analysis}

Statistical analysis was done using the

Statistical Package for the Social Sciences (SPSS software version 25, Chicago, Illinois). Mean \pm standard deviation (SD) and range for parametric numerical data, while median and interquartile range (IQR) were used for nonparametric numerical data. Student $t$-test was used to assess the statistical significance of the difference between two study group mean values of quantitative data. Mann Whitney Test (U test) was used to assess the statistical significance of the difference of a nonparametric variable between two study groups. ChiSquare test was used to examine the relationship between two qualitative variables.

One-way ANOVA was used to assess the statistical significance of the difference between more than 2 mean- values of quantitative data. The receiver operating characteristic (ROC) curves were used to determine the cutoff point, which shows the highest sensitivity and specificity of IL-35 in differentiating serum and tissue. For interpretation of results of tests of significance, significance was adopted at $\mathrm{p}<0.05$. 


\section{RESULTS}

Age and sex of the study groups are shown in table 1.

Table (1): Age and sex distribution among groups

\begin{tabular}{|l|l|l|l|l|l|}
\hline \multicolumn{2}{|c|}{} & Groups & \multicolumn{2}{l|}{ Control (N=22) } \\
\cline { 3 - 6 } \multirow{2}{*}{ Age } & Range & Patient (N=22) & \multicolumn{2}{l|}{$18-30$} \\
\cline { 2 - 6 } & Mean \pm SD & $22.32 \pm 4.77$ & $\mathbf{N}$ & $\mathbf{N}$ \\
\hline \multirow{2}{*}{ Sex } & Male & N & 50 & 16 & 72.7 \\
\cline { 2 - 6 } & Female & 11 & 50 & 6 & 27.3 \\
\hline
\end{tabular}

The present study showed that there was a highly statistically significant difference between patient and control regarding IL-35 level in serum and tissue (Table 2).

Table (2): Comparison between patient and control regarding IL-35 level in serum and tissue

\begin{tabular}{|c|c|c|c|c|c|}
\hline & \multicolumn{2}{|l|}{ Groups } & \multirow[t]{2}{*}{ Mann-Whitney } & \multirow[t]{2}{*}{ P value } \\
\hline & & Patient $(\mathrm{N}=22)$ & Control $(\mathrm{N}=22)$ & & \\
\hline \multirow{2}{*}{$\begin{array}{l}\text { IL-35 }(\mathrm{ng} / \mathrm{ml}) \\
\text { in serum }\end{array}$} & Median & 4.19 & 1.61 & \multirow[t]{2}{*}{74.00} & \multirow[t]{2}{*}{$<0.001 \mathrm{HS}$} \\
\hline & IQR & $2.28-4.81$ & $1.34-2.54$ & & \\
\hline \multirow{2}{*}{$\begin{array}{l}\text { IL-35 }(\mathrm{ng} / \mathrm{ml}) \\
\text { in tissue }\end{array}$} & Median & 551.96 & 134.82 & \multirow[t]{2}{*}{737.000} & \multirow[t]{2}{*}{$<0.001 \mathrm{HS}$} \\
\hline & IQR & $478.86-657.42$ & $118.72-167.66$ & & \\
\hline
\end{tabular}

HS = Highly significant difference

There was no statistically significant difference between grade of the disease regarding IL-35 level in serum and tissue (Table 3).

Table (3): Comparison between grade of the disease as regard IL-35 level in serum and tissue.

\begin{tabular}{|l|l|l|l|l|l|l|}
\hline \multicolumn{2}{|l|}{} & \multicolumn{3}{|l|}{ Grade } & $\begin{array}{l}\text { Significant } \\
\text { test }\end{array}$ & p value \\
\cline { 3 - 7 } & Mild & Moderate & Severe & $0.079 \mathrm{Ns}$ \\
\hline $\begin{array}{l}\text { IL-35 (ng/ml) } \\
\text { in serum }\end{array}$ & Mean \pm SD & $3.91 \pm 0.89$ & $3.24 \pm 0.31$ & $5.20 \pm 0.75$ & $\mathrm{~F}=2.908$ & \\
\hline $\begin{array}{l}\text { IL-35 (ng/ml) } \\
\text { in tissue }\end{array}$ & Mean \pm SD & $558.10 \pm 43.102$ & $594.21 \pm 16.52$ & $500.27 \pm 26.63$ & $\mathrm{~F}=0.226$ & $0.823 \mathrm{Ns}$ \\
\hline
\end{tabular}

NS = Non-significant difference

There was no statistically significant difference between courses of the disease as regard IL-35 level in serum and tissue (Table 4).

Table (4): Comparison between course of the disease as regard IL-35 level in serum and tissue

\begin{tabular}{|c|c|c|c|c|c|c|}
\hline & \multicolumn{3}{|l|}{ Course } & \multirow{2}{*}{$\begin{array}{l}\text { Significant } \\
\text { test }\end{array}$} & \multirow[t]{2}{*}{ p value } \\
\hline & & Progressive & Recurrent & Stationary & & \\
\hline $\begin{array}{l}\text { IL-35 }(\mathrm{ng} / \mathrm{ml}) \text { in } \\
\text { serum }\end{array}$ & Mean \pm SD & $3.74 \pm 0.47$ & $4.29 \pm 0.44$ & $2.85 \pm 0.56$ & $\mathrm{~F}=2.908$ & $0.079 \mathrm{Ns}$ \\
\hline $\begin{array}{l}\text { IL-35 }(\mathrm{ng} / \mathrm{ml}) \text { in } \\
\text { tissue }\end{array}$ & Mean \pm SD & $640.97 \pm 26.91$ & $517.13 \pm 94.45$ & $597.81 \pm 15.75$ & $\mathrm{~F}=0.226$ & $0.823 \mathrm{Ns}$ \\
\hline
\end{tabular}

NS = Non-significant difference

There was no statistically significant correlation between type of the lesion as regard IL-35 level in serum and tissue (Table 5).

Table (5): Comparison between type of the lesion as regard IL-35 level in serum and tissue

\begin{tabular}{|l|l|l|l|l|l|}
\hline \multicolumn{2}{|c}{} & \multicolumn{2}{l}{ Type of the lesion } & Significant test & p value \\
\cline { 3 - 6 } & Inflammatory & Comedone & & \\
\hline $\begin{array}{l}\text { IL-35 }(\mathbf{n g} / \mathbf{m l}) \text { in } \\
\text { serum }\end{array}$ & Mean \pm SD & $3.41 \pm 0.6$ & $4.42 \pm 0.22$ & $\mathrm{~T}=1.533$ & $0.141 \mathrm{Ns}$ \\
\hline $\begin{array}{l}\text { IL-35 }(\mathbf{n g} / \mathbf{m l}) \text { in } \\
\text { tissue }\end{array}$ & Mean \pm SD & $571.60 \pm 17.17$ & $559.74 \pm 20.63$ & $\mathrm{~T}=0.226$ & $0.823 \mathrm{Ns}$ \\
\hline
\end{tabular}

NS = Non-significant difference

Receive operative curve (ROC) revealed that the best cut-off point was $\leq 2.81$ (ng/ml) for IL-35 in serum and $\leq 211.45(\mathrm{ng} / \mathrm{mg})$ in tissue (Table 6). 
Table (6): Patient and control sensitivity and specificity to measure level of IL-35 in serum and tissue and ROC

\begin{tabular}{|l|c|c|c|c|c|c|c|c|c|}
\hline \multicolumn{1}{|c|}{ Cut off point } & AUC & Sensitivity & Specificity & +PV & $\mathbf{9 5 \%}$ Cl & $\mathbf{- P V}$ & $\mathbf{9 5 \%} \mathbf{C l}$ & $\mathbf{Z}$ test & p value \\
\hline $\begin{array}{l}\text { IL-35 (ng/ml) in } \\
\text { serum } \leq 2.81\end{array}$ & 0.847 & 86.36 & 68.18 & 73.1 & $\begin{array}{c}52.2- \\
88.4\end{array}$ & 83.3 & $\begin{array}{c}58.6- \\
96.4\end{array}$ & 6.083 & $<0.0001$ \\
\hline $\begin{array}{l}\text { IL-35 (ng/mg) in } \\
\text { tissue } \leq 211.45\end{array}$ & 0.945 & 95.45 & 95.45 & 95.5 & $\begin{array}{c}77.2- \\
99.9\end{array}$ & 95.5 & $\begin{array}{c}77.2- \\
99.9\end{array}$ & 9.654 & $<0.0001$ \\
\hline
\end{tabular}

\section{DISCUSSION}

Acne vulgaris is a multifactorial disease which is associated with pilosebaceous follicle and results in inflammatory and non-inflammatory lesions ${ }^{(\mathbf{8})}$. The pathogenesis of acne is attributed to increased sebum production, inflammatory processes, follicular hyperproliferation, and the proliferation of Propionibacterium acnes ${ }^{(9)}$.

Interleukin-35 (IL-35) is the latest addition to the IL-12 family. It is a heterodimeric cytokine, consisting of IL-12 p35 subunit and IL-27 $\beta$ subunit Epstein-Barr virus induced 3 (EBI3). Since its discovery, IL-35 has been shown to exhibit immunosuppressive activities, which are distinct from other members of IL-12 family. IL-35 is also unique in that it is expressed primarily by regulatory T-cells (Tregs) rather than by antigen-presenting cells (APCs) ${ }^{(10)}$.

Interleukin-35 (IL-35) can directly suppress effector T-cell proliferation and function and inhibit the differentiation of Th17 cells. It is also able to expand regulatory responses to promote tolerance to infections by generating a potent population of IL35-producing inducible Tregs (iTr35). As the new cellular sources of IL-35 such as CD8+Tregs, Bregs, and tolerogenic dendritic cells DCs (tolDCs) are identified, more immunoregulatory functions of this cytokine are explored ${ }^{(\mathbf{1 0})}$.

There are various findings of cytokines related to acne vulgaris, but no previous study correlates IL35 to acne vulgaris. In Egypt, to our knowledge, this is the first study to evaluate the serum and tissue level of IL-35 in lesional and non-lesional areas in acne vulgaris patients in relation to control group and correlating the results with grade of acne, type of the lesion and course of the disease.

This study included 2 groups: The patient group included 22 patients with acne vulgaris and the $2^{\text {nd }}$ group included 22 healthy. Diagnosis was made on clinical basis. Patients were of both sexes and their age ranged between (18-35).

By measuring the level of (IL-35) in serum its mean was 4.19 in the patient group and 1.61 in control group. The mean of IL-35 in tissue was 551.96 in the patient group, while in the control group it was 134.82 . These results revealed a highly statistically significant difference between patient and control regarding IL-35 level in serum and tissue.

In our study we expected this elevation to be in relation with grade of acne, type of the lesion and course of the disease, but exactly it was not. There was no statistical significant difference between grade and course of the disease and type of the lesion regarding IL-35 level in serum and tissue. Exactly we cannot explain this, but it may be due to low expression of IL-35 receptor on CD4+ T cells that may not be sufficient enough to suppress proinflammatory cytokines in acne patients like that proved in systemic lupus erythematosus as it was observed an increased level of plasma IL-35 together with low expression of IL-35 receptor on CD4+ T cells that may not be sufficient enough to suppress proinflammatory cytokines in SLE patients ${ }^{(\mathbf{1 1})}$.

We wish we could prove its anti-inflammatory rule in acne as proved in other diseases, or even explain the cause of its elevation as it has been shown that the lack or loss of functional regulatory IL-35 can lead to enhanced inflammatory immune responses, and hence increased incidence and severity of inflammatory diseases. Conversely, the induction of IL-35 expression can alleviate disease symptoms of inflammatory bowel disease, encephalomyelitis, and collagen-induced arthritis. Even though IL-35 can reduce the frequency and severity of arthritis and other inflammatory immune responses, there is limited knowledge on the in vivo immunoregulatory mechanism of IL-35 ${ }^{(11)}$.

The discovery that IL-35 can induce the conversion or expansion of lymphocytes to regulatory $\mathrm{B}$ and $\mathrm{T}$ cells has considerable implications for therapeutic use of autologous regulatory $\mathrm{B}$ and $\mathrm{T}$ cells in human diseases ${ }^{(\mathbf{1 2})}$.

We have the hope to bypass any obstacle of fighting effect if there is of IL-35 on this chronic miserable disease that affects young adults in the age that needs confidence and actually acne destroys this and if there is no relation we need more research to explain why this significant high elevation of both serum and tissue level of IL-35 in acne patients as compared to healthy controls in contrast to the study that proved the therapeutic rule of IL-35 in systemic induced lupus in mice ${ }^{(\mathbf{1 1})}$. 


\section{CONCLUSION}

Interleukin-35 (IL-35) is actively expressed in serum and lesional tissues of patients with acne vulgaris. Tissue and serum IL-35 are hypothesized to play a key role in acne cure at multiple points, through their anti-inflammatory actions but it may be hindered by unknown obstacles.

\section{REFERENCES}

1. Bergler-Czop B, Lis-Święty A, Brzezińska-Wcisło L et al. (2014): Antiphospholipid antibodies in localized scleroderma: The potential role of screening tests for the detection of antiphospholipid syndrome. Postepy Dermatologii I Alergologii, 31(2):65-70.

2. Rivera R, Guerra A (2009): Management of acne in women over 25 years of age. Actas Dermosifiogr., 100:33-7.

3. Plewig G (2010): How acne vulgaris develops. Hautarzt., 61:99-10.

4. Allan S, Song-Zhao G, Abraham $T$ (2008): Inducible reprogramming of human $\mathrm{T}$ cells into Treg cells by a conditionally active form of FOXP3 (J). Eur J Immunol., 38:3282-3289.

5. Yang J, Yang M, Htut T (2008): Epstein-Barr virusinduced gene 3 negatively regulates IL-17, IL-22 and RORgamma t. Eur J Immunol., 8:1204-1214.
6. Liu F, Tong F, He Y (2011): Detectable expression of IL-35 in CD4+ T cells from peripheral blood of chronic hepatitis B patients. Clin Immunol., 139:1-5.

7. Dreno B, Poli F, Pawin H, Beylot C et al. (2011): Development and evaluation of a Global Acne Severity Scale (GEA Scale) suitable for France and Europe. J Eur Acad Dermatol Venereol., 25:1:43-48.

8. Younis S, Javed Q (2015): The Interleukin-6 and Interleukin-1A gene promoter polymorphism is associated with the pathogenesis of acne vulgaris. Arch Dermatol Res., 30: 365-370.

9. Karadag A, Ertugrul D, Bilgili $S$ et al. (2012): Immunoregulatory effects of isotretinoin in patients with acne. British Journal of Dermatology, 167(2):433-435.

10.Song M, Ma X (2016): The immunobiology of interleukin-35 and its regulation and gene expression. US National Library of Medicine National Institutes of Health, 941:213-225.

11.Cai $Z$ (2015): Remission of systemic lupus erythematosus disease activity with regulatory cytokine interleukin (IL)-35 in Murphy Roths Large (MRL)/lpr mice. Clin Exp Immunol., 181(2): 253266.

12.Egwuagu C, Yu C, Sun L et al. (2015): Interleukin 35: Critical regulator of immunity and lymphocytemediated diseases. Cytokine Growth Factor Rev., 26(5):587-93. 